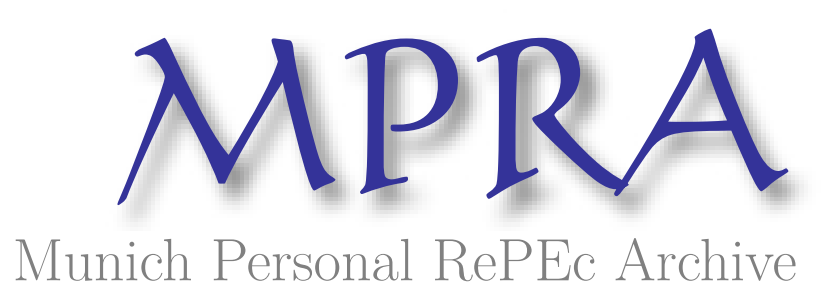

\title{
A simple model to evaluate relative urban conditions
}

Pareto, Vittorio Emmanuel

February 2009

Online at https://mpra.ub.uni-muenchen.de/13985/

MPRA Paper No. 13985, posted 14 Mar 2009 02:08 UTC 


\section{A Simple Model to Evaluate Relative Urban Conditions}

Vittorio E. Pareto IV 


\section{INTRODUCTION}

One of the main objectives of urban planning is to promote and assure a comprehensive development process. To achieve this purpose it is necessary to evaluate existing conditions, analyse trends, establish development strategies, define goals, specify projects and programs and allocate resources. The underlying assumption is that these projects and programs, when implemented, will upgrade the present pattern of urban conditions to an improved and more balanced pattern.

In practice, most projects and programs have a strong sectorial connotation, reflecting the urban administration structure. If there is no planning activity, each agency will propose its own development scheme based on its view of the urban reality, and set its own priorities and goals. As such, the more powerful sectors will tend to obtain a larger share of the available resources, while weaker sectors will compete for any remaining resources. Such a process will tend to aggravate distortions and inequalities throughout the urban landscape.

The main planning task, therefore, is to adopt a demand-oriented approach: guide the resource allocation process, dimensioning projects and programs according to a development strategy based on the urban conditions found in each area of the city. Under this principle, it is necessary to establish the performance levels each sector should have to improve the accessibility pattern to urban equipment, infrastructure and services.

Most sectorial agencies in the urban administration have their own development programs, which highlight their priorities, goals and strategies. Assessing the effective demand for these programs is often difficult, since resource allocation decisions tend to be subjective due to the lack of adequate means of comparison. How does one evaluate the need for housing improvements in one neighbourhood, vis-à-vis the demand for improvement in the water supply at another? How does one balance the public transportation expansion and the school upgrading program? A more accurate assessment of these issues is necessary to 
improve the resource allocation process and, ultimately, to attain higher public satisfaction with the results.

To dimension the degree to which each sector should improve its performance, it is necessary to evaluate the relative performance levels of all sectors. This is a challenging task. How does one identify and quantify the intensity and location of these actions? How does one assign resources among the several pressing issues? How does one evaluate the efficiency of the projects and programs in terms of achieving the original objectives?

This paper discusses a method which helps to answer some of these questions, and finds a reasonable balance between the various actions that will be developed by sectorial agencies throughout the urban space. It will also facilitate assessing the apparent sectorial performance in each urban area, by defining resource allocation criteria. By establishing sectorial goals, it will help to estimate the investment requirements to attain these goals.

Assessing sectorial conditions by urban location is normally done by assembling and analysing urban data. This is often discouraging. The data available for analysis are generally collected by several different agencies for their own specific objectives, frequently being either too general or too specific for planning purposes. Furthermore, the data sources rarely adopt the same spatial subdivision, since their particular information needs are based on their own operational characteristics. Data analysis can be especially difficult in the context of rapidly growing cities in developing regions, where data are often scarce, issues easily confused and resources extremely limited. Yet it is exactly in this context and for these reasons that a quantitative approach method should be preferred, assuring that the distribution of resources will be made according to the effective demand. Such an approach will contribute to reduce existing distortions in the spatial distribution of urban equipment and services, by focusing investments in the sectors and places where the unbalance is more acute. 
The tools available to planners are usually borrowed from related fields, ranging from economics and statistics to urban geography and business management. Baxter (1976), Chorley and Haggett (1976), and Krueckeberg and Silvers (1976) describe various concepts and analysis techniques commonly used in planning. Examples of simple yet efficient uses of quantitative techniques can be found in Oppenheim (1980), Spencer (1984) and Sweet (1985). The United Nations Centre for Human Settlements (Habitat) developed an Urban Data Management System (1981), demonstrating that urban data management and modelling systems can be based on small data sets and still provide the level of insight required by planners.

Currently, normal office software and notebook computers can perform all the basic data analysis required for urban planning except mapping. GIS software can provide this and many other resources for urban management tasks, yet are not essential for strategic planning, where a broader view is more important than the control of detailed information.

This paper will discuss a system to select and display urban data in a format that will facilitate appraising and quantifying the demand for sectorial improvements at each urban zone. This system can also facilitate the establishment of sectorial goals that should be attained to fulfil a predefined urban development strategy. Finally, it can contribute to the allocation of resources among the several sectors and thus help to quantify sectorial development programs.

The system proposed is based on using indicators to represent each urban sector. These indicators are derived from a small data base, in which the information is aggregated by zone thus providing the necessary spatial connotation. The indicators are then normalised, to allow direct comparison of the performance of each sector at each zone. Displaying the normalised indicators in graphic format facilitates data analysis and the evaluation of urban conditions among sectors and zones. Once the relative needs of each area are appraised, an 
interactive model is used to assist defining goals and estimating the demand for investments.

\section{URBAN INDICATORS}

While there is no perfect way to represent the conditions of each urban sector, it is common practice to assume that the sector's status can be appraised with reasonable accuracy by one or more indicators, which present a close proxy of these conditions. In this way, a national development level is usually represented by its income per capita, health conditions by infant mortality or life expectancy at birth, education by the literacy rate, and so on. While each indicator can only represent a particular aspect of the sector they belong to, they are able to convey the general level of performance of the sectors.

There is an immense amount of information that is collected regularly by various sectorial agencies. However, not all data are suitable to be used as indicators. Indicators should represent the performance of the selected sector reasonably well. Often there are cases where a single indicator does not conveniently represent its sector. In such an instance, it will be more appropriate to generate a compound indicator, aggregating the more relevant aspects of the sector. For comparative purposes, the resulting single value will represent better the performance of the sector than any of the individual factors by itself.

As an example, the performance of the water supply system could be assessed by a combination of two indicators, such as the ratio of dwellings with piped water supply and the volume of water supplied per capita per day. A simple compound indicator could be obtained by calculating the product of these two elements. As such, if $75 \%$ of the dwellings have piped water and the volume of water delivered is 60 litres per capita per day, the water indicator would be 45 . Likewise, if another zone has $85 \%$ of dwellings with piped water and receives 100 litres per capita per day, the value of its water indicator will be 85 . In this example, the water supply system of the latter zone would be relatively better than the 
first. If some factors are more important than others, a weighing system should be introduced, so that the final value reflects reasonably well the apparent sectorial conditions throughout the city.

Dividing of the city into zones is necessary to assess the urban conditions throughout the city. In principle, the zoning system should refer to existing neighbourhoods and be as homogeneous as possible. Data should be available for all the spatial subdivisions (zones) of the city, so that the conditions of the zones can be compared. This may be the greatest obstacle to overcome in obtaining data. Most data collecting agencies define their geographical subdivisions according to their own operational characteristics and these areas rarely coincide with the subdivisions adopted by other agencies. Furthermore, some sectors do not aggregate their information by area, but by network. Despite these constraints, it is usually possible to conceive a zoning system for which sectorial data are available.

A large number of valuable indicators can be assembled which represent well the urban context. For the purpose of this paper, the indicators should be limited to the sectors that can be controlled or directly influenced by the urban administration, such as land use, housing, infrastructure, local services, transportation, education, health, environmental quality, etc. Although other indicators may be very informative, if an aspect is beyond the local government's sphere of competence, it cannot be addressed by local projects or programs and therefore is redundant. To identify and dimension urban projects, therefore, the indicators selected should represent issues that can be improved by the local government, through its own financial and regulatory means, and by other levels of competence, that could be induced to participate in the process.

In practice, the group of indicators and the spatial subdivision system adopted tend to be a compromise between the relevance of the issue and the availability and representativeness 
of data. In Karachi, ${ }^{1}$ where this method was originally conceived, the city was divided into 58 analysis zones which were considered to be reasonably homogeneous for planning purposes. The land use typology and characteristics of each zone were further assessed by satellite and aerial photographs, which were used as an aid to interpolate data from agencies using different spatial subdivisions. The indicators selected in this project represented urban sectors such as economy (income per household and ratio of unemployment), housing (number of households per dwelling, ratio of formal and informal housing), water supply (ratio of dwellings with piped water and volume of water distributed per capita), sewer system (ratio of dwellings with sewers), power supply (ratio of dwellings with electricity), gas system (ratio of dwellings with gas), communications (ratio of lines per dwelling), transportation (time of travel), education (school attendance), health (distribution of health facilities), recreation (recreational area per capita), security (number of incidents per capita), and environment (water and air pollution, noise levels). Zonal data were obtained from a variety of sources, including special surveys promoted by the Karachi Development Authority.

Although indicators can be used to assess the performance of each sector at each zone, they may be insufficient in comparing the efficiency of two or more different sectors. If one zone receives an average of 60 litres of water per capita and another receives 100, the values immediately convey the information that the performance of the latter is better than the former. Yet this information does not show if the water supply is generous, meagre, or barely adequate. To assess the sectorial performance, it is necessary to select a parameter, to which the value of the indicators can be compared. If the standard adopted for an adequate distribution is 50 litres per capita per day, then both zones would have adequate performances. However, if the recommended volume is 400 litres, then both zones are very poorly serviced.

\footnotetext{
${ }^{1}$ Karachi Development Plan - UNCHS/KDA/PADCO/PEPAC (1989).
} 
Adopting an external parameter, such as an international standard or the national mean, poses a problem in itself. These standards are often unattainable or inappropriate by the prevalent economic or physical context. Local factors can strongly affect the performance of each sector, such as economic conditions, cultural patterns, technological level, the physical availability of the resource considered and its distribution conditions.

Another issue is finding a way to compare the performance of different sectors. How does one compare water supply with environmental pollution or quality of public transportation? In principle, one can relate each sector to an external standard, and then assess the local performance by evaluating these values. In this manner, if the indicator for the electricity sector is $90 \%$ of the electricity supply standard, and the indicator of the water sector is $80 \%$ of the water supply standard, one would infer that the electricity system is approximately $13 \%$ better than the water system. Yet, as discussed above, the use of external standards is not always adequate. Particular conditions of the city, such as topography, distance to supply centres and local climate can facilitate a better performance of some sectors, while restraining others. To be sure, external standards are very useful as a general reference, but should be avoided as the preferred evaluation benchmark.

Possibly the best way to appraise sectorial conditions of a particular zone would be to compare the value of the indicator with the urban mean. The urban mean reflects the response to the historical demand in each sector, in which the prevalent economic, social and physical conditions continuously play their part. Furthermore, the demand for a particular service tends to be more influenced by the performance levels in neighbouring zones than any proposed external value. For instance, if the highest supply level in the city is 100 litres per capita per day, the zone that has that level is the best serviced and thus has a lower claim for improvements than any other zone, even if the absolute value is substantially lower than the recommended supply. 
Under this assumption, zones with performance levels higher than the urban mean would demand relatively less investment for development than zones with performance levels lower than the mean. The demand for improvements in each sector would therefore tend to be consistent with the distribution pattern of the indicator values, as measured by the standard deviation of the sector. In a normal distribution pattern, about $64 \%$ of the results are within plus or minus one standard deviation and $94 \%$ within two standard deviations. As such, it follows that if the indicators are normalised (i.e. related to the normal distribution pattern), they will reflect better the relative performance of each sector at each zone. ${ }^{2}$

In their normalised format, indicators are not further measured by their specific units, but by their position in the distribution pattern according to the standard deviation of the sector. Since they now share the same basic reference, the indicators can be compared directly. Thus, by comparing the normalised values of the indicators, the sectorial 'needs' of each zone can be evaluated. Furthermore, by ranking and evaluating the relative performance of each sector and zone through different periods of time it is possible to monitor the process of development of each zone, and appraise the effect of specific policies, projects and programs. This technique also allows the quantification of the goals that should be attained to achieve a desired distribution of performance levels, making it easier to establish goals, define projects and allocate resources.

The procedure required to normalise the zonal indicators is quite simple. The normal value of the indicator is obtained by calculating the difference between the value of each zonal indicator and the mean for the sector, and dividing the result by the standard deviation of sectorial indicator, as follows:

$$
N_{i, j}=\frac{X_{i, j}-\bar{X}_{i}}{S_{i}}
$$

\footnotetext{
${ }^{2}$ This procedure assumes a normal distribution of the data. In other cases, log transforming the data can reduce its skewness, resulting in more interpretable results (Kovach, 1985).
} 
where $N_{i, j}$ is the normalised value of indicator $i$ for zone $j, X_{i, j}$ is the value of the indicator $i$ for zone $j, \bar{X}_{i}$ is the mean of indicator $i$ and $S_{i}$ is the standard deviation of the indicator $i$.

The values of the normalised indicators can be presented in a table, with columns representing the sectorial indicators and rows the spatial units (zones). As such, each column will represent a sectorial profile - the various performance levels of that particular sector throughout the city. Likewise, each row will represent a zonal profile - all the sectorial performance levels in that zone. These profiles can be displayed in graphic format, making it easier to visualise the variation of urban conditions by zone and by sector.

\section{IMPLEMENTING AN URBAN ASSESSMENT SYSTEM}

\subsection{Structure of the system}

A simple urban assessment system can be built using a typical spreadsheet. This option allows great flexibility and ease of use for data entry and updating, as well as easy generation of graphics and tables for analysis. Since all the data and programs can be stored in the spreadsheet and be linked together, every time the data are changed all recalculations are done automatically. This feature makes it possible to obtain updated indicator information each time the basic data are changed or revised.

The basic system is composed of three matrices with a similar format. The first, the 'basic data' matrix, is used as the main data base, storing all the sectorial data needed to build the indicators. All data input is made into this matrix. The second, the 'urban indicators' matrix, will calculate and display the zonal indicators, based on the values of the data base matrix. The third, the 'normalised indicator' matrix, will calculate and display the normalised values of the indicators. 
The three matrices have the same general format: the rows identify the zones, and the columns the specific attributes. As such, all three will have the same number of rows - one for each zone. The number of columns of the basic data base is the same as the data items needed to calculate the selected indicators. The indicator matrix has a similar format, except that the columns will identify the selected indicators. The normalised data matrix is identical to the indicator matrix, displaying the normalised values of the indicators.

In the indicator data base each cell holds the formulae that will retrieve data from the basic data base and calculate the value of the corresponding indicator. Additional rows are necessary to calculate the mean and standard deviation of each indicator. ${ }^{3}$ This procedure assumes a normal distribution of the data, a condition that sometimes is not met. The cells of the third matrix contain the formula to compute the normalised value of each indicator for each zone. Report generation is easily achieved by the application itself, displaying the data in tables and in graphic format.

While for most indicators a positive and higher value indicates better conditions, there are some where a negative value represents a better performance. This would be the case for indicators such as time of travel, in which a lower value indicates a more efficient transportation system. To facilitate analysing the profiles, the normalised indicators in which lower values represent better performances should be multiplied by minus one. This inversion will assign positive values to all sectors with better performances, so that they will be displayed in the upper part of the charts.

3 The spreadsheet formula used to calculate the standard deviation is: SD = @SQRT (@COUNT(list) / (@COUNT(list) - 1) * @ VAR (list)). 


\subsection{Implementing the system}

The first step in setting up this urban assessment system is to define the number of spatial units, or zones, and select the indicators that will be used to assess the urban conditions in those zones. The sectorial indicators will determine the data items that will be required. Once the number of zones, the data items and the indicators are defined, the spreadsheet matrices can be assembled, and data can be entered into the system. The values of the indicators, as well as the standard and normalised formats are then automatically computed and displayed.

A simplified example of the three matrices that compose the system is shown in the following pages, representing a city divided into 12 planning zones. Table 1 displays the basic data base and input matrix, containing all data necessary to run the system. Table 2 shows the indicator matrix, where the values of the indicators, the mean and the standard deviation are calculated for all sectors. Finally, Table 3 displays the normalised values of the indicators, which are used to draw the graphs for each indicator (sector profiles) and for each zone (zonal profiles). 


\begin{tabular}{|c|c|c|c|c|c|c|c|c|c|c|c|c|c|c|}
\hline Zone & Population & $\begin{array}{r}\text { School } \\
\text { Age } \\
\text { Population }\end{array}$ & Area & $\begin{array}{c}\text { Formal } \\
\text { Dwellings }\end{array}$ & $\begin{array}{l}\text { Informal } \\
\text { Dwellings }\end{array}$ & $\begin{array}{r}\text { Dwellings } \\
\text { with } \\
\text { Water }\end{array}$ & $\begin{array}{l}\text { Dwelligns } \\
\text { w/ Sewer }\end{array}$ & $\begin{array}{l}\text { Dwellings } \\
\text { w/ Electr. }\end{array}$ & $\begin{array}{l}\text { Dwellings } \\
\text { w/ Phone }\end{array}$ & $\begin{array}{c}\text { Travel } \\
\text { Time }\end{array}$ & $\begin{array}{r}\text { Distance } \\
\text { to } \\
\text { Centre }\end{array}$ & $\begin{array}{r}\text { Primary } \\
\text { Enrolment }\end{array}$ & $\begin{array}{l}\text { Health } \\
\text { Centres }\end{array}$ & $\begin{array}{r}\text { Recreation } \\
\text { Area }\end{array}$ \\
\hline 1 & 12,500 & 1,200 & 90 & 2,250 & 250 & 2,300 & 1,400 & 2,400 & 1,150 & 3.00 & 0.50 & 900 & 8.00 & 4.00 \\
\hline 2 & 24,200 & 7,200 & 140 & 3,600 & 900 & 3,700 & 3,000 & 4,400 & 2,600 & 18.00 & 2.50 & 6,500 & 9.00 & 5.00 \\
\hline 3 & 35,100 & 12,000 & 270 & 4,250 & 2,100 & 4,500 & 2,300 & 6,200 & 3,800 & 20.00 & 3.00 & 10,400 & 12.00 & 7.00 \\
\hline 4 & 8,500 & 2,300 & 45 & 1,050 & 250 & 1,100 & 800 & 1,250 & 1,000 & 10.00 & 1.00 & 1,800 & 4.00 & 1.00 \\
\hline 5 & 18,300 & 5,400 & 120 & 3,150 & 340 & 3,200 & 2,700 & 3,400 & 2,400 & 35.00 & 4.20 & 4,800 & 9.00 & 1.00 \\
\hline 6 & 45,300 & 10,200 & 270 & 8,000 & 1,800 & 8,200 & 6,500 & 9,600 & 6,400 & 45.00 & 5.70 & 8,200 & 12.00 & 5.00 \\
\hline 7 & 24,900 & 7,200 & 140 & 2,400 & 2,100 & 2,500 & 1,200 & 4,300 & 1,200 & 17.00 & 2.30 & 6,500 & 13.00 & 12.00 \\
\hline 8 & 37,700 & 9,800 & 180 & 5,250 & 1,200 & 5,350 & 4,500 & 6,300 & 2,300 & 10.00 & 1.40 & 7,500 & 15.00 & 12.00 \\
\hline 9 & 23,500 & 6,800 & 210 & 3,700 & 100 & 3,750 & 3,600 & 3,600 & 1,200 & 10.00 & 1.40 & 5,200 & 12.00 & 10.00 \\
\hline 10 & 19,400 & 5,800 & 180 & 3,400 & 800 & 3,900 & 3,850 & 3,900 & 1,200 & 34.00 & 3.70 & 4,800 & 10.00 & 13.00 \\
\hline 11 & 8,700 & 2,800 & 48 & 1,400 & 600 & 1,650 & 1,500 & 1,900 & 500 & 8.00 & 0.90 & 2,500 & 5.00 & 3.00 \\
\hline 12 & 21,800 & 7,400 & 234 & 3,600 & 500 & 3,800 & 3,650 & 3,800 & 900 & 39.00 & 5.60 & 6,500 & 8.00 & 9.00 \\
\hline Total & 279,900 & 78,100 & 1,927 & 42,050 & 10,940 & 43,950 & 35,000 & 51,050 & 24,650 & 20.75 & 2.68 & 65,600 & 117.00 & 82.00 \\
\hline
\end{tabular}

Table 1 - Urban Data Base 


\begin{tabular}{|c|c|c|c|c|c|c|c|c|c|}
\hline Zone & $\begin{array}{c}\text { Informal } \\
\text { Dwellings } \\
(\%) \\
\end{array}$ & $\begin{array}{r}\text { Dwellings } \\
\text { w/ water } \\
(\%) \\
\end{array}$ & $\begin{array}{r}\text { Dwellings w/ } \\
\text { sewer (\%) } \\
\end{array}$ & $\begin{array}{r}\text { Dwellings w/ } \\
\text { Electr.(\%) } \\
\end{array}$ & $\begin{array}{r}\text { Dwellings w/ } \\
\text { phone (\%) }\end{array}$ & $\begin{array}{r}\text { Travel } \\
\text { Time / } \\
\text { Km } \\
\end{array}$ & $\begin{array}{r}\text { Prim. School } \\
\text { Attendance } \\
(\%) \\
\end{array}$ & $\begin{array}{r}\text { Health } \\
\text { Centre/10,000 } \\
\end{array}$ & $\begin{array}{l}\text { Recreatonal } \\
\text { Area/10,000 }\end{array}$ \\
\hline 1 & 10.00 & 92.00 & 56.00 & 96.00 & 46.00 & 6.00 & 75.00 & 6.40 & 3.20 \\
\hline 2 & 20.00 & 82.22 & 66.67 & 97.78 & 57.78 & 7.20 & 90.28 & 3.72 & 2.07 \\
\hline 3 & 33.07 & 70.87 & 36.22 & 97.64 & 59.84 & 6.67 & 86.67 & 3.42 & 1.99 \\
\hline 4 & 19.23 & 84.62 & 61.54 & 96.15 & 76.92 & 10.00 & 78.26 & 4.71 & 1.18 \\
\hline 5 & 9.74 & 91.69 & 77.36 & 97.42 & 68.77 & 8.33 & 88.89 & 4.92 & 0.55 \\
\hline 6 & 18.37 & 83.67 & 66.33 & 97.96 & 65.31 & 7.89 & 80.39 & 2.65 & 1.10 \\
\hline 7 & 46.67 & 55.56 & 26.67 & 95.56 & 26.67 & 7.39 & 90.28 & 5.22 & 4.82 \\
\hline 8 & 18.60 & 82.95 & 69.77 & 97.67 & 35.66 & 7.14 & 76.53 & 3.98 & 3.18 \\
\hline 9 & 2.63 & 98.68 & 94.74 & 94.74 & 31.58 & 7.14 & 76.47 & 5.11 & 4.26 \\
\hline 10 & 19.05 & 92.86 & 91.67 & 92.86 & 28.57 & 9.19 & 82.76 & 5.15 & 6.70 \\
\hline 11 & 30.00 & 82.50 & 75.00 & 95.00 & 25.00 & 8.89 & 89.29 & 5.75 & 3.45 \\
\hline 12 & 12.20 & 92.68 & 89.02 & 92.68 & 21.95 & 6.96 & 87.84 & 3.67 & 4.13 \\
\hline Average & 20.65 & 82.94 & 66.05 & 96.34 & 46.52 & 7.73 & 83.99 & 4.18 & 2.93 \\
\hline STD & 11.89 & 11.60 & 20.81 & 1.86 & 19.50 & 1.16 & 5.96 & 1.08 & 1.78 \\
\hline
\end{tabular}

Table 2 - Indicators 


\begin{tabular}{r|r|r|r|r|r|r|r|r|r}
\hline Zone & Inf. Dwellings & Water & Sewer & Electricity & Telephone & Transport & Education & Health & Recreation \\
\hline 1 & 0.8951 & 0.7809 & -0.4830 & -0.1819 & -0.0266 & 1.4934 & -1.5085 & 2.0559 & 0.1517 \\
\hline 2 & 0.0543 & -0.0619 & 0.0296 & 0.7723 & 0.5773 & 0.4593 & 1.0537 & -0.4270 & -0.4846 \\
\hline 3 & -1.0448 & -1.0407 & -1.4335 & 0.6972 & 0.6832 & 0.9189 & 0.4481 & -0.7050 & -0.5249 \\
\hline 4 & 0.1189 & 0.1444 & -0.2168 & -0.0993 & 1.5590 & -1.9538 & -0.9616 & 0.4870 & -0.9839 \\
\hline 5 & 0.9168 & 0.7542 & 0.5437 & 0.5809 & 1.1408 & -0.5174 & 0.8208 & 0.6834 & -1.3375 \\
\hline 6 & 0.1915 & 0.0632 & 0.0133 & 0.8697 & 0.9633 & -0.1395 & -0.6042 & -1.4179 & -1.0247 \\
\hline 7 & -2.1880 & -2.3603 & -1.8926 & -0.4205 & -1.0179 & 0.2944 & 1.0537 & 0.9639 & 1.0605 \\
\hline 8 & 0.1716 & 0.0005 & 0.1786 & 0.7169 & -0.5568 & 0.5085 & -1.2518 & -0.1864 & 0.1422 \\
\hline 9 & 1.5147 & 1.3570 & 1.3785 & -0.8600 & -0.7660 & 0.5085 & -1.2619 & 0.8579 & 0.7440 \\
\hline 10 & 0.1343 & 0.8547 & 1.2310 & -1.8689 & -0.9202 & -1.2550 & -0.2073 & 0.9026 & 2.1166 \\
\hline 11 & -0.7866 & -0.0379 & 0.4301 & -0.7187 & -1.1033 & -0.9962 & 0.8873 & 1.4513 & 0.2911 \\
\hline 12 & 0.7105 & 0.8397 & 1.1040 & -1.9625 & -1.2596 & 0.6624 & 0.6445 & -0.4726 & 0.6728 \\
\hline
\end{tabular}

Table 3 - Normalised Indicators (negative indicators multiplied by $\mathbf{- 1}$ ) 
In this example, the indicator for housing conditions is represented by the ratio of informal dwellings. This indicator is calculated by dividing the number of informal dwellings by the total number of dwellings (sum of formal and informal dwellings). The condition of the water supply system is represented by the ratio of dwellings with water connection, calculated by dividing the total number of dwellings with water connection by the total number of dwellings. The indicators for the other infrastructure systems, such as sewers, electrically and telephone, are calculated in the same way. The indicator for the transportation system is represented by the average time of travel divided by the distance to the centre of employment. Education is represented by the ratio of primary school enrolment, obtained by dividing the number of pupils enrolled by the total school age population. Finally, the sectors of health and recreation are assessed by the ratio of health facilities per capita and the recreational area per capita, respectively.

To facilitate describing the system, no aggregated indicators were used and no attempt was made to balance the relative importance of the sectors by using a weighing system. In practice, however, both alternatives should be considered.

\subsection{Analysing urban conditions}

Although relative urban conditions can be directly assessed by analysing the values of the normalised indicators, it is easier and more rapid to compare the sectorial and zonal profiles in graphic format. In this example, bar charts of sectorial and zonal profiles were generated by the spreadsheet application. The vertical bars display the normalised values of indicators representing the sector or zone. These values can be positive or negative, corresponding to performance levels higher or lower than the urban mean. The urban mean of normalised indicators is always zero. As such, values near the centre line indicate average performance conditions, while high positive or negative values indicate distribution distortions - unusually high or low performance levels. 
Sectorial profiles display the varying performance levels of a particular sector throughout the urban space. While bar charts allow identifying the sectors with low performance conditions, it Is often more convenient to display the relative conditions in the more traditional map format. This can be done by adopting a ranking system and generating theme maps for each sector. A five level ranking system is normally adequate, displaying very good, good, average, bad and very bad performance levels. This format allows one to visualise the location of the regions where urban conditions demand prompt action.

Figures 1 and 2 illustrate two zonal profiles (zones 2 and 7) from the example:

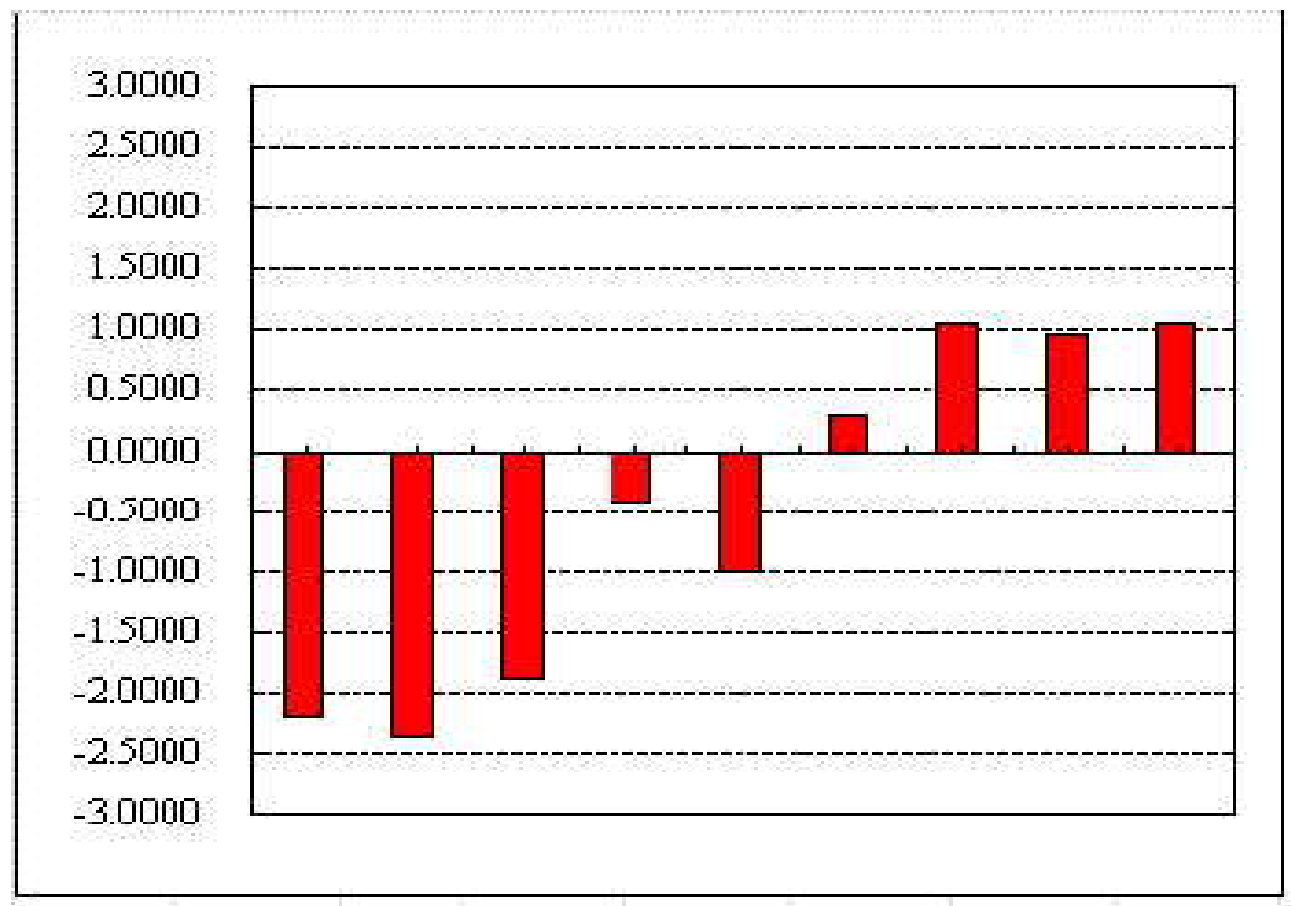

Figure 1 - Zonal Profile (zone 7)

Zone 7 presents very low performance levels in the housing and infrastructure sectors (indictors 1, 2 and 3), although the performance in the other sectors is better than average. 
Thus, the situation of housing and infrastructure should deserve further analysis to identify the causes of the situation and the actions that are suitable to improve these conditions.

Zone 2, on the contrary, depicts a zone apparently without any significant issue. All indicators are reasonably near or above the urban mean.

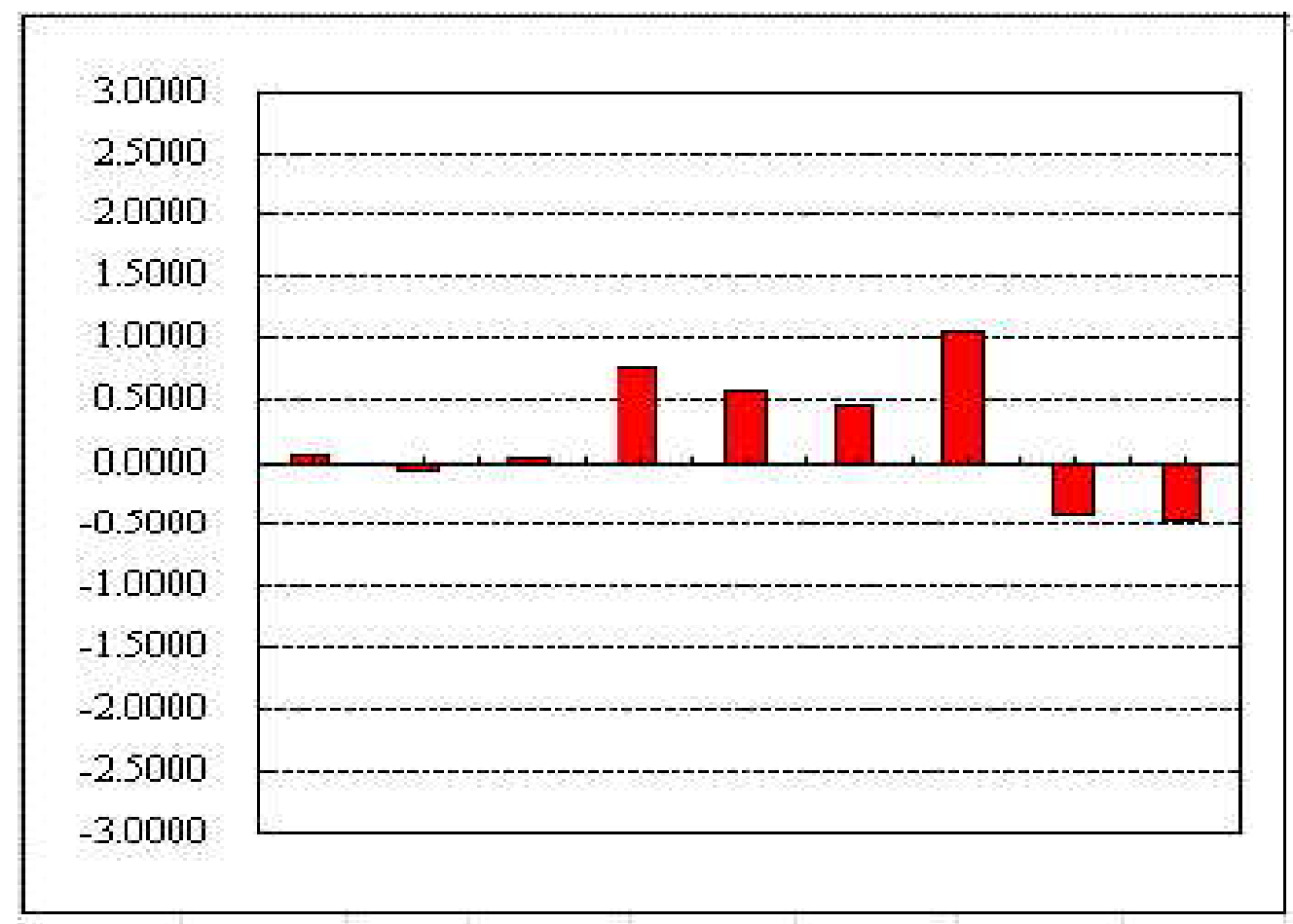

Figure 2 - Zonal Profile (zone 2)

The following Figures 3 and 4 illustrate two sectorial profiles, displaying the conditions of housing and water supply (represented by the distribution of informal dwellings and the number of water connections). The housing profile highlights that the housing issue is more acute in zone 7, followed by zones 3 and 11 . In the same way, the water supply system is extremely deficient in zones 7 and 3 . In a similar way, all zones and sectors should be analysed, identifying the critical issues and their spatial location. 


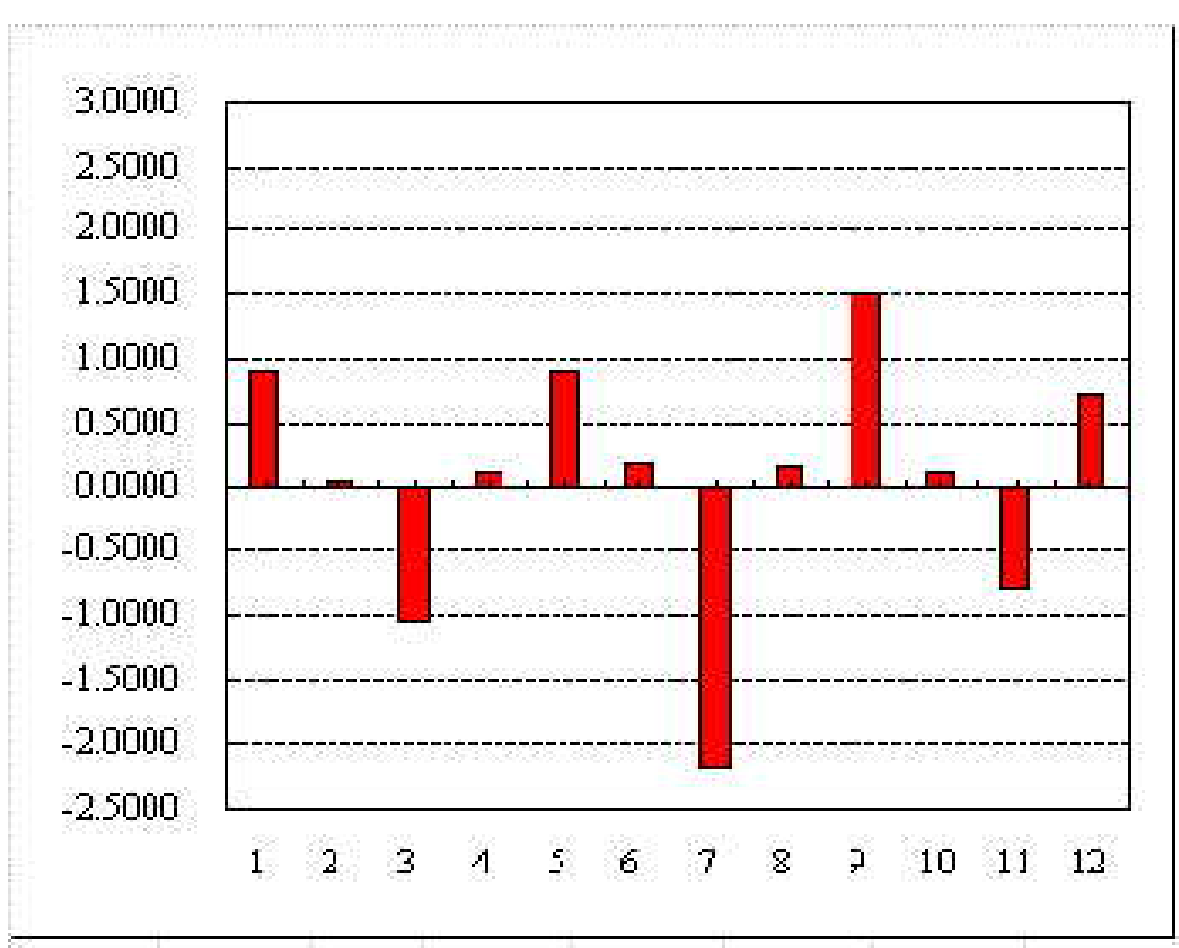

Figure 3 - Honsing (ratio of informal dwellings)

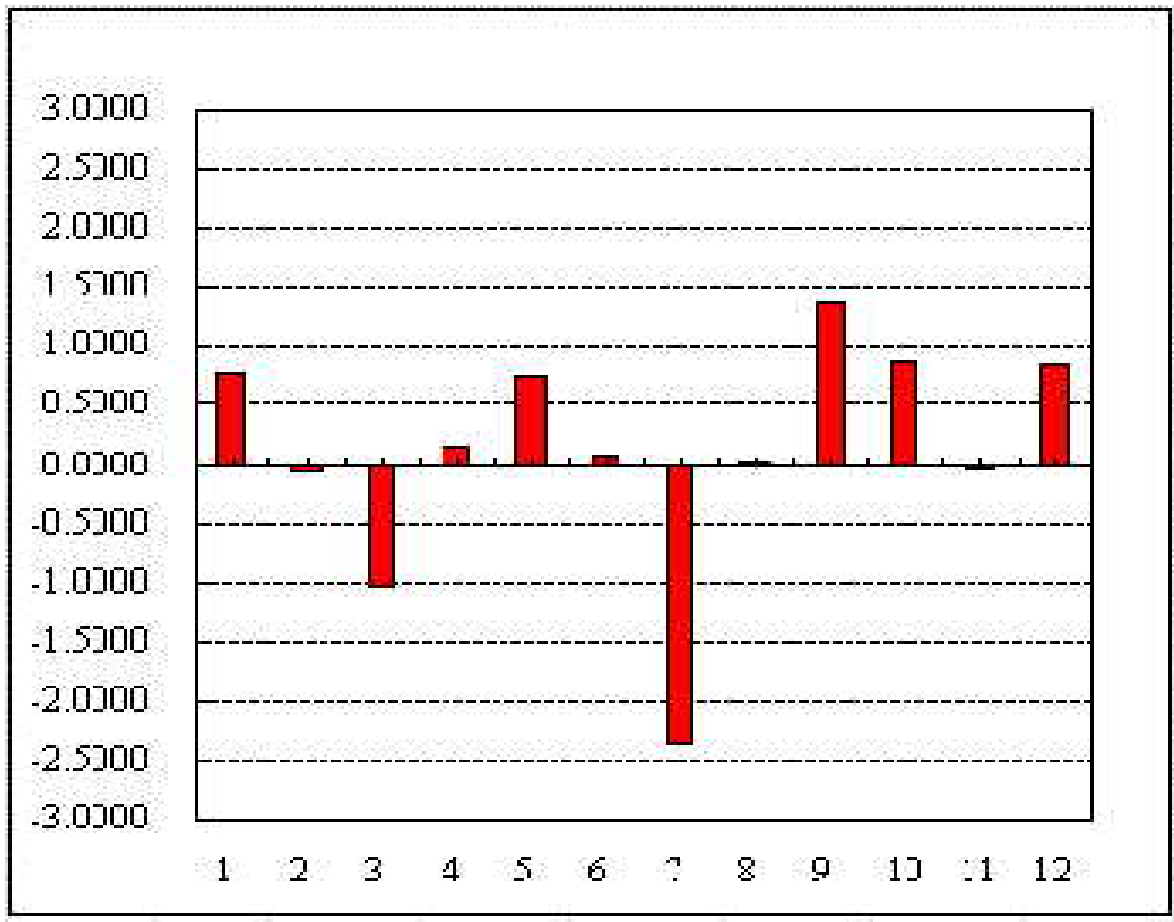

Figure 4 - Wate supply Gunditiuns (I atiu ur watea canineaxiuns) 
One of the main advantages of using zonal profiles to analyse urban conditions is the possibility of displaying the spatial distribution of the relative performance of each sector in a compact format. This characteristic allows the rapid visualisation of critical issues and their location. However, the urban indicators acting as proxies for the various urban sectors cannot be expected to represent with great precision any particular issue. Furthermore, since the zonal values are the average for each zone, a more heterogeneous distribution within that zone will not be noticed. As such, before dimensioning sectorial actions or development programmes, the target areas and issues in question should be examined in detail, considering the particular aspects and circumstances prevailing in each area.

\subsection{Development strategies}

After identifying the main issues and their locations, it is necessary to define a policy to deal with these issues. It would be unrealistic to suppose that the prevailing urban conditions could be raised much beyond the average levels found in similar cities, or much above the urban national average. If such a policy is adopted, not only will it require massive investments - probably beyond the local financing capacity - but it will also attract migration from other centres which will tend to revert the urban conditions to the previous levels.

More pragmatic alternatives might be to consider establishing policies which aim to raise the zonal conditions below average to the urban mean, or to another pre-established level. This process by itself will raise the average conditions of the city. Another policy could establish that all zones should be improved, by a fixed percentage or by a variable rate aiming to reduce zonal inequalities. The latter policy could be implemented by directing selffinancing schemes to the 'best' zones, and concentrating public investments on improving the 'worst' areas.

These examples are only some of the options for establishing urban development policies. Others may focus on particular issues, such as environmental quality, social development, 
public transportation or infrastructure. Still others may be defined according to prevalent political trends.

Variations in the urban conditions are assessed by changes in the values of the indicators. When new data are entered in the input matrix the performance indicators are automatically calculated. Therefore, the system can be used interactively, by modifying the data at the input matrix until a desired pattern of performance levels is obtained. These selected changes could then become the initial development objectives.

\subsection{Defining development goals}

An urban development programme obviously should not focus in simply improving the particular aspects that are used in the indicators. The actions proposed must be comprehensive and reflect local conditions, opportunities and constraints that cannot be shown only through the indicators. Furthermore, a program to enhance the water system at one place may also be used to improve neighbouring areas at a marginal cost. On the other hand, there are thresholds of supply that must be observed. Power plants, telephone exchanges, water supply lines, roads, bridges, schools, parks, etc. all have standard production capacities or more economical dimensions that must be considered when defining development goals. As such, the initial goals resulting from the local demand should be revised to consider these physical, economical and operational opportunities and constraints.

It is important to stress that improving a sector, as for instance the electrical supply system, does not mean merely increasing the number of electrical connections, but comprehensively upgrading the whole system: from power generation and transmission to energy conversion and local distribution, as required to satisfy the established goals. Since the comprehensive upgrading of each system has inherent industrial and operational 
thresholds, this factor should have a major influence in the establishment of the sectorial goals, aiming to achieve more cost effective programmes.

\section{CONCLUSIONS}

The system discussed is reasonably simple to implement, requires relatively few data and can provide a basic guideline to dimension development projects. As such, it can be a valuable tool to discuss planning alternatives. The major obstacle to overcome is to assure that each zone is reasonably homogeneous so that the zonal indicators can reflect reasonably well the existing conditions. While the example shown was made simple for demonstration purposes, only availability of data limits expanding the system to more complex levels. One such option could be incorporating cost functions, reflecting cost variations, operational thresholds and other factors. Yet expansion should be limited to the extent to which the performance of the model can be easily appraised. If the model is to be extended, it is preferable to use independent modules so that the results of each can be appraised separately. These modules could eventually be linked together to present consolidated results. This procedure would allow more control over the system, avoiding distortion in the results from possible data errors or programming limitations. 


\section{BIBLIOGRAPHY}

Baxter, R.: Computer and Statistical Techniques for Planners. Methuen, London, 1976.

Chorley, R. and Haggett, P. (Editors): Socio-Economic Models in Geography. Methuen, London, 1976.

Gordon, A. D.: Classification: Methods for the Exploratory Analysis of Multivariate Data. Chapman \& Hall, London, 1987.

Hartigan, J.: Clustering Algorithms. Wiley, New York, 1975.

Jain, A. and Dubes, R.: Algorithms for Clustering Data. Prentice Hall, Englewood Cliffs, New Jersey, 1988.

Kaufman, L.: Finding Groups in Data. Wiley, New York, 1990.

Kelley, A.: Modelling Urbanization and Economic Growth. IIASA, Laxenburg, Austria, 1980.

Kovach, W.: Multivariate Statistical Package. Bloomington, Indiana, 1985.

Krueckeberg, D. and Silvers, A.: Urban Planning Analysis: Methods and Models. John Wiley, New York, 1976.

Mohan, R.: Urban Economic and Planning Models - Assessing the Potential for Cities in the Development Countries. John Hopkins University Press, Baltimore, 1979.

Oppenheim, N.: Applied Models in Urban and Regional Analysis. Prentice Hall, Englewood Cliffs, New Jersey, 1980.

Pareto, V. E. et al.: Karachi Development Plan, KDA/UNCHS/PADCO, Karachi, 1989.

Spencer, R.: Cluster Analysis, BYTE, September 1984.

Sweet, H.: The Use of Clustering Techniques on an Apple Computer, The American Biology Teacher, January 1985. 